\title{
Reestruturação imobiliária no Rio de Janeiro (RJ): agentes e transformações urbanas na área central da cidade
}

Estate restructuration in Rio de Janeiro (RJ): actors and transformations in the inner city area

Restructuration immobilière à Rio de Janeiro (RJ) : acteurs et transformations urbaines dans le centre-ville

Re-estructuración inmobiliaria en Río de Janeiro: Agentes y transformaciones urbanas en el área central de la ciudad

\section{Gabriel Silva de Araujo Teixeira}

\section{OpenEdition}

Journals

Edição electrónica

URL: http://journals.openedition.org/espacoeconomia/1563

DOI: $10.4000 /$ espacoeconomia. 1563

ISSN: 2317-7837

Editora

Núcleo de Pesquisa Espaço \& Economia

Refêrencia eletrónica

Gabriel Silva de Araujo Teixeira, « Reestruturação imobiliária no Rio de Janeiro (RJ): agentes e transformações urbanas na área central da cidade », Espaço e Economia [Online], 6 | 2015, posto online no dia 10 agosto 2015, consultado o 20 abril 2019. URL : http://journals.openedition.org/ espacoeconomia/1563; DOI : 10.4000/espacoeconomia.1563

Este documento foi criado de forma automática no dia 20 Abril 2019.

(c) NUPEE 


\section{Reestruturação imobiliária no Rio de Janeiro (RJ): agentes e transformações urbanas na área central da cidade}

Estate restructuration in Rio de Janeiro (RJ): actors and transformations in the inner city area

Restructuration immobilière à Rio de Janeiro (RJ) : acteurs et transformations urbaines dans le centre-ville

Re-estructuración inmobiliaria en Río de Janeiro: Agentes y transformaciones

urbanas en el área central de la ciudad

Gabriel Silva de Araujo Teixeira

\section{Introdução}

1 A condição de sede dos Jogos Olímpicos de 2016 traz à cidade preocupações com sua própria aparência diante da visibilidade internacional que se intensificará. Talvez seja essa a explicação para o repentino "zelo" que tomou conta da Prefeitura do Rio e dos investidores privados e fez emergir um oportuno discurso de revitalização da cidade. No entanto, diante dessa preocupação paisagística e superficial se ocultam mudanças nas relações e estratégias capitalistas para a produção do espaço urbano e nas relações com o poder local. Nesse contexto, o poder público se mostra absolutamente vulnerável aos movimentos de reestruturação espacial e de acumulação capitalista por meio de operações imobiliárias e mostra a face neoliberal da gestão urbana atual.

2 As mudanças decorrentes de um intenso movimento de construção e verticalização das áreas degradadas que circundam o centro da cidade do Rio de Janeiro, revelam um importante processo de reestruturação urbana no qual identificamos uma forte presença de capital internacional e fazem da cidade um ponto de observação da ação que o capitalismo contemporâneo tem imposto às cidades. Para isso, analisamos o fenômeno na 
estrutura urbana carioca a partir da investigação dos agentes imobiliários, averiguando empiricamente as novas formas oriundas desse processo e o que elas representam de significante na produção social do espaço urbano da cidade. $O$ recorte adotado nessa pesquisa envolve o Centro do Rio de Janeiro e proximidades (como os bairros Cidade Nova, Saúde, Gamboa, Santo Cristo e Caju) e se fundamenta na intenção de abordar as transformações urbanas ilustrativas da lógica de acumulação capitalista através do capital imobiliário.

3 Os elementos que orientam essa interpretação partem dos empreendimentos imobiliários que foram escolhidos para análise (Quadro 1). São oito ao total, divididos em duas regiões na área central do Rio de Janeiro, a Zona Portuária e o Centro I. Uns ainda em construção e outros já concluídos, esses edifícios simbolizam as forças hegemônicas que tem dominado a cidade e dão concretude as alterações abordadas.

4 Uma breve análise desse quadro mostra que a construção da cidade está à cargo de agentes internacionais, como construtoras, incorporadoras e fundos financeiros de origens distintas, como Singapura, Estados Unidos, Inglaterra e Alemanha. Identifica também a construção de aproximadamente 80 mil metros quadrados de uso corporativo. A presença dos agentes identificados na construção desses empreendimentos aponta significativas mudanças nas relações de propriedade do solo urbano.

Quadro 1 : Empreendimentos imobiliários divididos por microregião

\begin{tabular}{|c|c|c|c|c|}
\hline & Proprietário & Construtora & Tamanho & Uso \\
\hline \multicolumn{5}{|l|}{ Zona Portuária } \\
\hline Porto Brasilis & $\begin{array}{c}\text { Fibra ExpertGrupo } \\
\text { Vicunha }\end{array}$ & Gafisa & $\begin{array}{c}\text { Terreno: } 1.635 \mathrm{~m}^{2} \\
\text { Pavimentos: } 21\end{array}$ & Corporativo \\
\hline Port Corporate Tower & Tishman Speyer & Tishman Speyer & $\begin{array}{c}\text { Temeno: } 13.000 \mathrm{~m}^{2} \\
\text { Pavimentos: } 22\end{array}$ & Corporativo \\
\hline Porto A tlântico & Odebrecht & Odebrecht & & \\
\hline Leste & & & Terreno: $16.681 \mathrm{~m}^{2}$ & Comporativo/Hoteleiro \\
\hline Oeste & & & Temeno: $11.851 \mathrm{~m}^{2}$ & Corporativo \\
\hline $\begin{array}{c}\text { Holiday Inn Porto } \\
\text { Maravilha }\end{array}$ & Odebrecht & Odebrecht & $\begin{array}{l}\text { Terreno: } 4.000 \mathrm{~m}^{2} \\
\text { Pavimentos: } 33\end{array}$ & Hoteleiro \\
\hline \multicolumn{5}{|l|}{ Centro I } \\
\hline ECO Sapucaí & GIC Real State & Hocht ief do Brasil & Terreno: $21.387 \mathrm{~m}^{2}$ & Corporativo \\
\hline Cidade Nova II & Zech Group & Hocht ief do Brasil & Terreno: - & Corporativo \\
\hline $\begin{array}{c}\text { Centro Empresarial } \\
\text { Senado }\end{array}$ & Brasil Phoral & Whore & Terreno: $15.000 \mathrm{~m}^{2}$ & Corporativo \\
\hline $\begin{array}{c}\text { Passe io Corporate } \\
\text { (Grupo Opportunity) }\end{array}$ & Grupo Oppotunity & Dominus & $\begin{array}{c}\text { Terreno: } 9.142 \mathrm{~m}^{4} \\
\text { Pavimentos: } 17\end{array}$ & Corporat ivo \\
\hline
\end{tabular}

Fonte: elaboração do autor, 2015

5 A princípio a administração pública dissemina a ideia que os empreendimentos podem ser vinculadas às Olimpíadas e ao processo denominado de urbanismo olímpico atribuindo a esse evento uma lógica causal. Diante de uma expectativa festiva quanto ao legado do megaevento, todo tipo de transformação urbana é associada ao evento, como se fosse esse sua causa. Resguardadas a relação que existe entre uma e outra, as transformações que 
trataremos aqui são por nós identificadas muito mais com a lucratividade almejada pelas construtoras e incorporadoras na construção da cidade, pois como afirma Pereira ${ }^{1}$, "se o megaprojeto implica inovação e um impacto que transforma a cidade, nem sempre aponta para o desenvolvimento da vida urbana, mas quase sempre para o uso das potencialidades a serem instrumentalizadas pelo setor econômico"

6 Somado à isso, o arranjo político trans-escalar é elemento importante na reestruturação em curso no Rio de Janeiro. A aliança entre Governo Federal, Estadual e Prefeitura conflui para o andamento das máquinas e capitais que tocam as obras. A presença de agentes como Caixa Econômica Federal, Banco do Brasil e Petrobras apontam à intersecção capital privado-público e poder local-global.

\section{A cidade entre as reestruturações}

7 Tais transformações seguem a tendência de "reestruturação urbana" apontada por Smith (2007), onde o centro urbano seria "dominado por funções executivas, financeiras e administrativas de alto nível". Desse modo, a cidade procura inserir-se em um fluxo corporativo mundial, derivado em parte da necessidade das grandes empresas, assim como dos fluxos de investimentos de capitais na construção, de modo que o urbano se reestrutura para o mundo corporativo. No caso em análise, identifica-se a reafirmação e intensificação da primazia de um centro urbano voltado ao mundo dos negócios.

8 A reestruturação urbana refere-se à estrutura funcional da cidade, mas as transformações propelidas pelo capital imobiliário acontecem não apenas em torno da função dentro da estrutura, "mas em virtude da natureza mesma dos espaços e lugares criados e produzidos" (HARVEY, 2014) que fomentam a urbanização para a dinâmica da acumulação de capitais por meio da urbanização. A estrutura urbana fica submetida ao potencial de lucro que pode oferecer no processo de construção, levando à análise ao processo de construção em si. É nesse sentido que se identifica outra reestruturação: a "reestruturação imobiliária".

9 É através da produção imobiliária que o processo de acumulação capitalista é objetivado e transforma a cidade contemporânea. Pereira (2006) nomeia esse processo de "reestruturação imobiliária", traduzindo-se em artefatos arquitetônicos que possuem o aspecto mediador entre os demais processos que ocorrem na ordem distante e na ordem próxima, ou seja, sendo o imobiliário o objeto síntese dos diversos processos que constituem a produção social do espaço. Segundo o autor, a reestruturação imobiliária pode ser definida por duas maneiras,

"Primeiro, é uma percepção da mudança urbana a partir da dinâmica imobiliária abrangendo um entendimento da especificidade das formas de propriedade, que se funda na valorização imobiliária local, mas que se associa à dimensão global da acumulação pela noção de reestruturação. Segundo, é um imbricamento da dimensão social e da dimensão espacial gerando uma unidade por onde se observa o filtro da dinâmica imobiliária e a hierarquia das formas de produção do espaço que toma relevo nos processos socioespaciais da atual relação espaço-tempo." (2006, p.48)

10 Portanto, a mudança está no modo de produzir o imobiliário e os processos que essa produção encerra e não na intensificação da produção, pois se antes era a industrialização que envidava a produção social do espaço, hoje é o urbano que encarna as táticas do capital e se constitui como "força motriz da expansão capitalista" (LENCIONI, 2008). 
11 Enquanto estratégia territorial, a reestruturação imobiliária é parte do capitalismo financeiro que associou construção à bolsa de valores, e com sua virtude especulativa instrumentaliza o espaço, no que Pereira corrobora

“(...) a reestruturação imobiliária encontra especificidade num particular movimento de valorização do capital e da propriedade imobiliária, que tende a funcionar e a existir como capital, porque essa propriedade associada ao financeiro e à indústria passam a oferecer uma sobrevida ao capital, capaz de diferenciar e particularizar a sua acumulação com relação ao conjunto de outras possibilidades na atual reestruturação capitalista." (2006, p.48)

12 Nesse contexto de articulação entre forças que assume o espaço, a receptividade aos agentes internacionais por parte do poder político local faz com que o município do Rio de Janeiro nesse ano que completa 450 anos seja presenteado com verdadeiros "Cavalos de Tróia”, “didática metáfora" aplicada por Santos (1977 apud PEREIRA, 2014) para evidenciar o risco predatório que podem significar tais investimentos à cidade.

13 Não foge da compreensão que as formas em construção têm seu teor global e não se restringem às datas esportivas. O atual Prefeito da cidade, Eduardo Paes, que em entrevista ao jornal Valor (2014) declarou: “Olimpíada e Copa do Mundo não é só evento, é uma decisão geopolítica". o interesse em jogo suscita outras questões, como a concessão de terras da união à interesse privado de caráter internacional; o predomínio de salas corporativas em detrimento de habitações de interesse social; a seletividade do poder público com uma área urbana restrita de 5 milhões de $\mathrm{m}^{2}$ em um município com mais que 1 milhão de $\mathrm{km}^{2}$ etc. Neste trabalho, nos limitaremos à expor os principais agentes envolvidos na configuração da reestruturação imobiliária em andamento.

14 A área de destaque atualmente nas manchetes e no ideário dos cidadãos quando se fala em obras e transformações no Rio é a Zona Portuária, local de grande interesse dos investidores e de ações significativas no que dizem respeito à revitalização e reformas urbanas. No entanto, o capital (imobiliário) constantemente está à procura da criação de novas localizações que possam potencializar seu lucro.

15 Assim, outras ações foram mapeadas fora da Zona Portuária. Para efeito desse estudo, fezse necessário regionalizar a área central do Rio em duas microrregiões (como mostra a figura 1): a Zona Portuária, que obedece ao limite estabelecido pela Área de Especial Interesse Urbanístico, abrangendo os bairros Caju, Santo Cristo, Gamboa e Saúde; e o Centro I, envolvendo Cidade Nova e Centro. 
Figura 1 - Localização dos empreendimentos imobiliários: Zona Portuária e Centro I

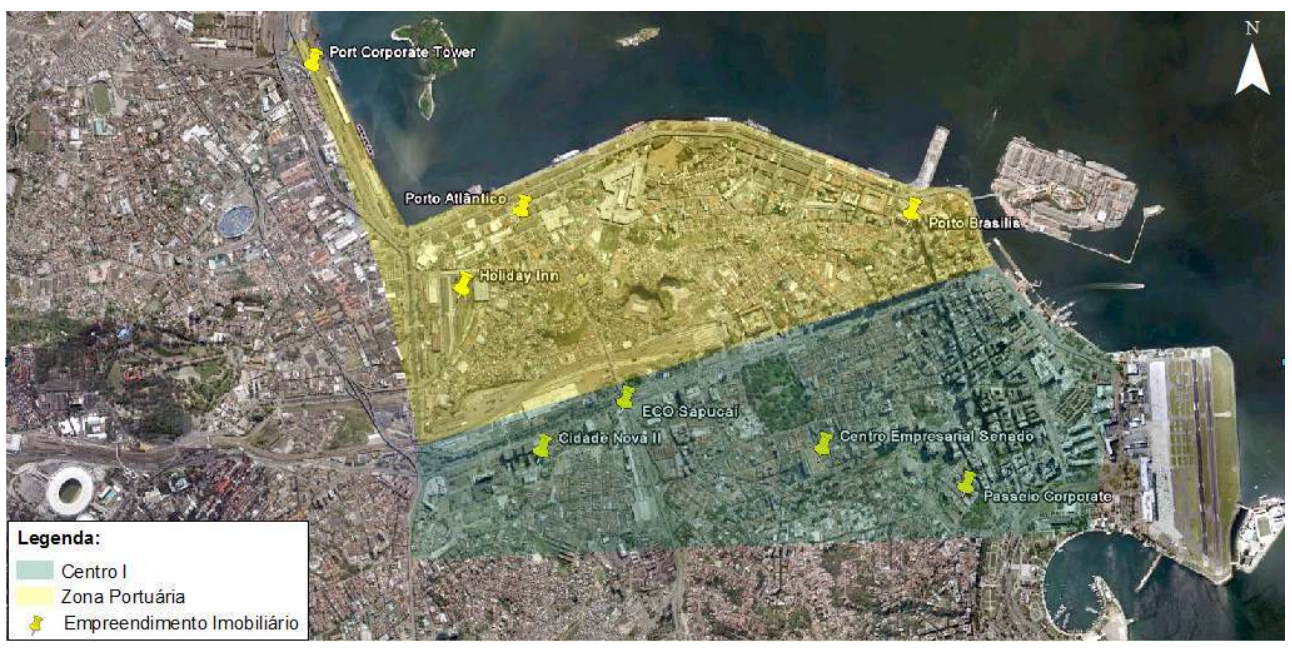

Fonte: Elaborada pelo autor, 2015

\section{Zona Portuária}

No espaço social ficam registrados na paisagem as práticas e processos sócio-espaciais característicos de cada modo de produção, fazendo coexistir diferentes sistemas de objetos. É assim que o "trabalho morto" convive com "trabalho vivo" numa relação dialética de compreensão do espaço social (SANTOS, 2012). A paisagem da região portuária do Rio de Janeiro torna evidente essa sucessão de formas e funções presentes tanto materialidade social quanto nas atividades ali desenvolvidas. $\mathrm{Na}$ área portuária ainda estão presentes os antigos galpões ligados à atividade portuária da então capital federal, em parte do século XX; bem, agora, é o cenário para os empreendimentos imobiliários ilustradores dos enormes investimentos no setor atualmente.

A justaposição de formas não só evidencia o surgimento do novo, enquanto o antigo para no tempo em inércia, pois as mesmas políticas que fazem o chamamento aos investimentos imobiliários inéditos também se preocupam em revitalizar essa parte histórica da cidade. A reforma do degradado e a construção do novo são direcionadas por políticas urbanas específicas para essa região. Construir, revitalizar e dar cor às formas de uma parcela cinza da cidade, escurecida pela sombra da Perimetral. Nessa missão, investidores imobiliários, construtoras e poder público se uniram para dar luz ao Porto Maravilha.

18 A parceria tem origem na Operação Urbana Consorciada da Região do Porto do Rio (OUC), promovida para a gestão da Área de Especial Interesse Urbanístico da Zona Portuária, ambas medidas previstas no Estatuto da Cidade (10.257/2001). Junto com a Concessionária Porto Novo, formada pela OAS Investimentos e Construtora, Odebrecht Investimentos e Construtora, Carioca Engenharia e Zi Participações S.A., a Prefeitura criou A Companhia de Desenvolvimento Urbano da Região do Porto do Rio de Janeiro (Cdurp) para ser sua porta-voz na operação.

19 Agentes internacionais também estão presentes nessa região. Não como "concorrentes", pois, capital imobiliário nacional e internacional se fundem na realização desses empreendimentos. Quatro exemplos concretos podem evidenciar esse caminho, tratam-se 
de dois edifícios concluídos nos últimos três anos, o Port Corporate Tower e o Porto Brasilis, e dois empreendimentos ainda em construção, o Hotel Holiday Inn Porto Maravilha e o Porto Atlantico Bunisses.

20 No tempo atual, os investidores capitalistas não investem na construção de habitações para reprodução da força de trabalho tradicional da era industrial e, no espaço, o capitalismo descobriu outras vias para a acumulação, além de outros fatores locacionais do processo de produção que alteram a configuração espacial. Deste modo, "há uma dissolução do urbano, no sentido de que o urbano como lócus da reprodução da força de trabalho tende a se dissolver" (PEREIRA, 2011) e se constituir como local da reprodução do capital. 0 projeto Porto Maravilha e os empreendimentos da área são expoentes desse processo.

21 Exemplo concreto nesse sentido é o edifício Porto Brasilis, construído sobre a vigência do Porto Maravilha, que é um ícone da nova organização espacial e produtiva que se configura no estado. $O$ empreendimento alia o investimento financeiro no mercado imobiliário e empreendimentos industriais que se instalam no estado do Rio de Janeiro. 0 empreendimento é realizado pela Gafisa (empresa construtora) com forte inversão de capital estrangeiro e com estrutura considerada de "edifício inteligente", e destina-se a ser a sede da Nissan, empresa de presença inédita no Brasil que inaugurou sua primeira fábrica no Brasil no município de Resende, no interior do Estado do Rio de Janeiro, em 2011.

Os "cavalos de Tróia" necessitam do apoio do Estado para potencializar suas operações, abrindo espaço para suas exigências. A liberdade que o capital necessita, segundo Vainer (2010), veio no contexto econômico e ideológico neoliberal, com a flexibilização do planejamento urbano moderno. Como afirma o autor, "enquanto o Consenso de Washington e o ajuste estrutural, tanto nos países centrais quanto nos periféricos, reconfiguravam as economias nacionais, um reajuste e um novo consenso urbano se impunham."

O poder público ao adotar essas medidas sanciona a "Cidade de Exceção" (Vainer, 2010), onde se assume a característica assimétrica entre interesses público e privado, sendo o poder privado o privilegiado pelas exceções, que se tornam a regra.

o novo consenso urbano que se refere o autor é a colocação da cidade como um ator competitivo, com as possibilidades de desenvolvimento urbano atrelada às oportunidades que o movimento espontâneo do mercado pode acarretar. Para esse efeito, através de um planejamento estratégico a cidade é gerida para buscar eficiência econômica a partir de seus espaços e se apresentar na rede internacional como local apto a qualquer investimento. Porém, a possibilidade destacada do discurso do planejamento estratégico é que o capital procura oportunidades para sua reprodução, e não para o desenvolvimento dos citadinos. Elemento que aponta nessa direção é a financeirização da produção imobiliária.

O movimento de negociações no balcão do mercado financeiro que envolvem CEPACs direciona a análise ao mercado financeiro imobiliário. Certificado de Potencial Adicional de Construção (CEPAC) é comercializado no mercado financeiro para a captação de recursos para os investimentos públicos na Área Especial de Interesse Urbanístico (AEIU). O público alvo da venda são investidores que construirão no local e pretendem fazer grandes obras. No entanto, como a comercialização é feita no mercado financeiro, 
qualquer um pode comprar, mesmo que não possua imóvel na área, podendo imprimir um caráter especulativo ao Certificado (CARVALHO FILHO, 2005).

O caso da Caixa Econômica Federal pode ilustrar essa transação: a Prefeitura do Rio, através da CDURP disponibilizou no mercado 6.436.722 CEPACs no valor inicial de $\mathrm{R}$ $\$ 545,00$ cada (MUNICÍPIO DO RIO DE JANEIRO, 2012), em leilão na plataforma de negociação virtual Cetip Net, tendo a Caixa como banco depositário dos recursos obtidos da transação. No entanto, foi a própria Caixa quem comprou os Certificados (desembolsando R $\$ 3,5$ bilhões com recursos do FGTS) e viabilizou as obras urbanísticas da região. Em seguida, a Caixa Econômica, através do Fundo de Investimento Imobiliário Porto Maravilha (FIIPM), colocou no ano 2012 em oferta secundária 100 mil CEPACs, que foram á leilão segundo edital da BM\&F Bovespa (Segundo Prospecto) no valor de $\mathrm{R}$ $\$ 1.150,00$ cada. Possuidora dos CEPACs, o FIIPM passou a atuar como investidor parceiro em alguns empreendimentos. Essa transação colocou a Caixa Econômica como importante agente das alterações espaciais nessa região.

Objetivado desse processo, o empreendimento imobiliário Port Corporate Tower, conta com investimento da Caixa Federal. Artefato inaugural dessa relação capital internacional-nacional/poder público-privado na região, o Port Corporate Tower é uma torre de 22 andares de escritórios construída pela parceria entre o Fundo de Investimento Imobiliário Porto Maravilha da Caixa Econômica e a norte americana Tishman Speyer que tem sede em Nova York, responsável ainda pela realização da Torre Ventura, também no Rio de Janeiro, e pela Torre Norte em São Paulo (SP). O edifício corta verticalmente o horizonte dos longos galpões degradados estendidos na linha do porto no bairro do Caju, próximo aos quilômetros iniciais da Avenida Brasil e anuncia consideráveis mudanças. Mudanças não apenas no visível, mas no processo da produção social do urbano.

No terreno estava localizada o antigo Moinho Marilu, implodido em 2011. Segundo Daniel Cherman, presidente da Tishman Speyer (em entrevista reproduzida pela Associação de Dirigentes de Empresas do Mercado Imobiliário, 2013), a escolha pela Zona Portuária é "em razão das limitações geográficas do Centro".

Outros empreendimentos imobiliários que apontam nessa direção são o Porto Atlântico e o Holiday Inn Porto Maravilha. Ambos geridos por capitais internacionais, ambos construídos por uma construtora nacional, a Odebrechet. O Holiday Inn Porto Maravilha será um hotel de 33 pavimentos em avançado estágio de construção. Pertence ao InterContinental Hotels Group (IHG), grupo britânico que opera redes de hotéis em todos os continentes e é a maior do mundo em quesito número de quartos (World Ranking 2013 Of Hotel Groups And Brands).

Já o Porto Atlantico Business Square será um complexo comercial com sete edifícios contendo salas corporativas, salas comerciais e quartos de hotel construídos em dois terrenos, um com $16.681 \mathrm{~m}^{2}$ e outro com $11.851 \mathrm{~m}^{2}$. Por enquanto, quatro edifícios estão em construção: um edifício corporativo, outro de salas comerciais, um hotel Novotel e um hotel Ibis, os dois da rede hoteleira francesa Accor Hotels.

31 Quanto à população carioca (que sem investimento na reprodução da força de trabalho $\mathrm{e}$ a utilização do solo urbano para acumulação) fica de fora dos limites da Área Especial de Interesse Urbanístico (AEIU) da Região do Porto do Rio no mais amplo sentido. Seja através das remoções que os moradores mais antigos na região estão sofrendo ${ }^{2}$, seja por meio do aprofundamento do abismo existente entre decisão popular e políticas públicas urbanas. $\mathrm{O}$ distanciamento entre cidadãos mais afastados da cidadania $e$ as decisões sobre 
uma parcela territorial da cidade coloca em questão: quem irá usar esse espaço? Diante dos pesados investimentos em turismo e funções corporativas, podemos falar de um uso internacional da cidade.

O arranjo econômico dos megaeventos e o caráter permissivo das leis urbanas adotadas tornam a cidade chamariz do capital imobiliário e permitem a privatização do espaço ao entregarem ao setor privado a decisão sobre os rumos da cidade, transmitindo ao capital imobiliário o protagonismo nas ações que reestruturam a Zona Portuária do Rio. Assim, o que se percebe é que todo o discurso de revitalização da cidade do projeto Porto Maravilha faz parte de um projeto esvaziado de intenções próprias, por ser ele mesmo mais consequência das alterações das relações espaciais, do que indutor dessas transformações.

o paradoxo fica nítido na paisagem: grandes torres de arquitetura arrojada sendo erguidas entre a estrutura depauperada da região, projetando a "fachada globalizada" (FIX, 2009) e escondendo um processo de reestruturação nefasto, que coloca a cidade em função do capital. Nenhum projeto de cidade que diga respeito ao cotidiano e a vivência de seus cidadãos e sua diversidade; pouco foco no projeto de habitação social; nenhuma intenção de construir uma cidade dinâmica e de acesso democrático à vida urbana (ODETTE, 2014).

\section{Centro I}

As alterações na cidade não se restringem ao Porto. A busca por novas localizações por parte do capital imobiliário transborda da Zona Portuária, cruzando a Avenida Presidente Vargas, indo da Cidade Nova à Lapa. Tais endereços não entram no discurso de revitalização para Olimpíadas, mas constituem extensos metros quadrados de terras urbanas que já se encontram vinculadas aos edifícios corporativos. Exemplo disso é o terreno de $21.387 \mathrm{~m}^{2}$ que pertencia a cervejaria AMBEV e foi vendido em 2011 para ser construído um edifício de escritórios onde antes funcionava uma fábrica da cerveja Brahma.

O edifício chamado ECO Sapucaí é uma obra póstuma de Oscar Niemeyer e presenteia a paisagem da região pelo virtuosismo típico do arquiteto. Chama atenção o heliponto na cobertura da obra, incorporando à arquitetura a velocidade que exige as transações do capital. Os 120 mil metros cúbicos de concreto usados na construção evidenciam o peso do capital imobiliário internacional. A realizadora do empreendimento, a Hemisfério Sul Investimentos, é uma gestora de fundos com captação de recursos no mercado internacional. No final de 2014, a obra foi comprada pelo fundo soberano de Singapura (GIC Real State).

Importante agente nessa área é a Petrobras. Recentemente foi responsável por dois grandes empreendimentos imobiliários, o Edifício Cidade Nova II, sede da BR Distribuidora e o Centro Empresarial Senado. O Edifício Cidade Nova II foi construído pela Hochtief do Brasil, pertencente à holding alemã Zech Group, e sediará a BR Distribuidora. A empresa contratada para gerir o projeto foi a Confidere, braço na atuação imobiliária do Grupo Synthesis, com larga atuação na Cidade Nova.

o Centro Empresarial Senado foi construído pela WTorre, que diferente das outras construtoras que buscam dinheiro na bolsa de valores, procurou se expandir financeiramente através de empréstimos em bancos nacionais. $O$ resultado foi uma 
grande dívida e a pressão para se inserir no mercado financeiro. Foram realizadas duas tentativas não bem sucedidas de levantar recursos através da venda de ações, o que fez a construtora vender o edifício para um grupo financeiro, o Brasil Plural, numa mega transação imobiliária de 1,2 bilhão de reais.

Os fundadores do Brasil Plural são ex-sócios do Banco Pactual, banco investigado por ações irregulares na bolsa de valores pela Comissão de Valores Mobiliários (CVM) juntamente com Grupo Opportunity, que encabeça outro grande empreendimento no Centro, entre a Cinelândia e a Lapa. O que está em construção é o Passeio Corporate, numa área de $70 \mathrm{mil} \mathrm{m}^{2}$ para uso corporativo, constituído por 3 torres de 17 andares. $\mathrm{O}$ Grupo visa ampliar seus investimentos imobiliários nessa região do Rio de Janeiro. Como aponta reportagem do jornal Folha (2012), o Grupo comprou 42 imóveis antigos na Rua da Carioca. As edificações são tombadas, o que impede a alteração da fachada. Resta aguardar para verificar se outro empreendimento imobiliário vai furar a lei vigente e derrubar os centenários casarões.

Os bancos de investimento Brasil Plural e Opportunity possuem ações na Bolsa de Valores brasileira, a BM\&F Bovespa. A estratégia de integração entre setor imobiliário e financeiro tem se intensificado no Brasil; e analisando essa estratégica, Lencioni aponta outro elemento para a reestruturação imobiliária. Segundo ela, "A abertura de capitais na bolsa de valores significa, claramente, para uma empresa, a ampliação das possibilidades de financiamento externo, que é diferente daquele procedente de financiamentos obtidos junto a bancos e instituições financeiras." (2014, p.42). Maior o financiamento, menor as dívidas e maior potencial econômico para um possível investimento no aumento do banco de terrenos, imprescindível para o sucesso de um empreendimento imobiliário. Traduzindo no espaço, a especulação sobre os terrenos vazios da cidade.

A extensão das transformações urbanas para essa área manifesta a pouca relação direta que existe entre megaeventos e a reestruturação da cidade. As obras estão fiéis ao projeto de tornar o Rio de Janeiro vendível, é o que as forças que atuam nessa região conjecturam. A localização nada tem a ver com o processo, o capital imobiliário não se restringe à Zona Portuária, pois não é o endereço que determina. Trata-se da intencionalidade dos agentes em ação ou, como afirma Fix (2009), "uma imposição espacial de poder econômico e político". E enquanto imposição segue os ditames dos que possuem interesse no local.

\section{Considerações Finais}

41 A análise empírica das transformações urbanas no Rio de Janeiro nos remete a questões quanto ao uso do solo, que se inclina à reafirmação do Centro da cidade como local de funções corporativas, executivas e financeiras; e quanto ao processo de produção do espaço, que apresenta nova característica através da produção imobiliária. Em outras palavras, procuramos expor como a reestruturação imobiliária se configura como uma importante tática do capital imobiliário, e de como esse processo se desenvolve no urbano a partir da realidade em curso na cidade. E, além disso, como a contextualização do Rio de Janeiro diante de alguns fluxos, tanto da ordem próxima quanto da ordem distante, contribuem na desmistificação sobre o determinismo dos megaeventos na elaboração da problemática urbana carioca.

42 O impasse estabelecido é o seguinte: "a política urbana tende a cobrir a diferença entre a urbanização real e o verdadeiro problema urbano que persistentemente é reposto por 
meio de falsas soluções." (PEREIRA, 2014). A intenção desse artigo foi abordar a urbanização real, o que nos leva a dois pontos importantes que a observação dessas práticas espaciais sugere para reflexão.

Primeiro, a mudança nas relações de propriedade imobiliária identificada através da reestruturação imobiliária aponta uma significativa parcela do solo urbano carioca em posse de agentes internacionais. As implicações disso nas relações espaciais da cidade se materializarão no correr do tempo, sendo difícil uma identificação precisa no momento.

o que se pode apreender por enquanto é que as táticas de acumulação através do urbano desses agentes internacionais podem comprometer o futuro da cidade ao injetar em curto prazo grande investimento nas construtoras nacionais, que se veem animadas com as parcerias internacionais. $O$ caso do hotel Holiday Inn Porto Maravilha é um exemplo desse risco, tendo em vista que a construção do empreendimento é responsabilidade e propriedade da nacional Odebrecht, e o operador hoteleiro é o mundial InterContinental Group, que ao menor ruído de perdas pode fazer fugir seu capital, enquanto que o capital nacional investido no ambiente construído poderá se tornar ruína.

Segundo ponto de reflexão é o distanciamento que tal dinâmica causa entre citadinos e a cidade, seja na relação de propriedade do solo propriamente dita, ou na relação de poder que o cidadão comum enfrenta com empresários. Isso porque a prefeitura se mostrou subserviente aos interesses do capital imobiliário, de modo que os planejamentos urbanos foram alterados, passando a ter a qualidade de não planejar, como respalda o Estatuto da Cidade ao permitir "a regularização de construções, reformas ou ampliações executadas em desacordo com a legislação vigente.". Desse modo, são os investidores privados que zelam pela cidade, apropriando-se do espaço público para uso restrito e seletivo.

Nesse distanciamento, uma parcela territorial da cidade se privatiza. No entanto, ao contrário do que a lógica poderia supor, não são os investidores privados que financiam todo enquadramento do território em seus interesses, mas é o poder público. A dinâmica estabelecida à primeira vista parece coerente: fazer o zoneamento especial de um território e comercializar Certificados (os CEPACs) para levantar fundos destinados às reformas urbanas, sem precisar de recursos públicos. Mas, qual a cidade que se espera produzida por investidores imobiliários e construtoras? Uma cidade cara.

Nesse sentido, o economista Carlos Lessa questiona: “Cidade pra quem?". Se a cidade é gerida como empresa, tem o princípio de gerar lucros. Se tiver por princípio gerar lucro, os usos da cidade ficam comprometidos, pois se tornam selecionados através da ótica lucrativa. De acordo com Lessa,

"A projeção da ideia de pensar a cidade como empresa, priorizando a competição, tem um reflexo espantoso: aumenta fantasticamente o poder dos empresários em relação àquela cidade. Desloca da representação os outros atores, que passam a estar subordinados à lógica do capital. Significa que ao capital tudo, e à população os benefícios derivados da atividade empresarial. Mas não o pensamento voltado aos moradores." (2013)

Tal seletividade tem por reflexo no espaço duas características nefastas: i) fazer políticas e agir em um território delimitado específico, previamente garantido os lucros e segregando o restante da cidade; ii) e, portanto, aprofundar o fosso da desigualdade sócio espacial.

Assim, a "transformação-produção-construção" do espaço social tem por conteúdo síntese esses artefatos arquitetônicos (PEREIRA, 2006) que elaboram a concretude de um espaço urbano global subordinado; ou internacionalizado através dos agentes 
identificados, os quais dão o tom do desenvolvimento urbano da cidade. 0 fluxo que eles impõem no Rio de Janeiro partem dos mais diversos locais do mundo e vem encontrar aqui o lugar para suas benesses de acumulação.

A mediação que tais empreendimentos encerram se mostra nítida no contexto de globalização e de reorganização da propriedade do solo urbano. Grandes parcelas do solo urbano que passam a pertencer aos fundos de investimentos sem cara e sem corpo, misterioso tanto em suas intenções presentes quanto o planejamento futuro da cidade. A face que conhecemos é a utilização cada vez maior do solo urbano como objeto de acumulação, entregando os rumos da cidade à oscilação insana do mercado financeiro.

Por ser um processo em desenvolvimento, não compreendemos ainda em sua totalidade os impactos que podem surgir quando assistimos um escritório em Nova Iorque decidir a localização de um edifício de 20 andares na Zona Portuária; ou quando um fundo de investimentos de Singapura é dono de um terreno de $20.000 \mathrm{~m}^{2}$ na margem da Av. Presidente Vargas. $O$ que podemos deduzir é que essas práticas espaciais tem tornado o Rio de Janeiro numa vitrine fundiária, expondo ao capital imobiliário a melhor parcela da cidade que lhes interessar.

A exclusão de quem habita a cidade do poder de decisão ilustra bem como essa tem sido produzida para atender demandas internacionais e corporativas. Ilustra também a alienação no que diz respeito à produção do espaço, sendo levados os habitantes locais a assistirem apenas, reduzidos à plateia do espetáculo urbano, quando a efetivação de uma cidade democrática exige a participação na construção não só através do cotidiano alienado, mas pelo planejamento participativo que vá de encontro ao capital imobiliário e à financeirização da cidade; uma cidade que ouça sua população e que se transforme por ela, e não ao contrário.

\section{BIBLIOGRAPHY}

CARVALHO FILHO, José dos Santos. Comentários ao Estatuto da Cidade. Rio de Janeiro: Editora Lumen Juris, 2005.

FIX, Mariana. Uma ponte para a especulação - ou a arte da renda na montagem de um "cidade global". Caderno CRH. Dossiê: Finanças, Políticas e Território. Salvador, v.22, n.55, p.41-63, Jan./Abr. 2009.

HARVEY, David. Cidades Rebeldes: Do direito à cidade à revolução urbana. São Paulo: Martins Fontes, 2014.

LENCIONI, Sandra. Reestruturação imobiliária: uma análise dos processos de concentração e centralização do capital no setor imobiliário. Revista de Estudios Urbanos Regionales, Chile, vol.40, n¹20, 2014.

LESSA, Carlos. Cidade para quem? Revista de Economia Fluminense, Rio de Janeiro, ano VII, n.13, p.12-13, 2013.

MUNICÍPIO DO RIO DE JANEIRO. Prospecto de registro da Operação Urbana Consorciada da Região do Porto do Rio de Janeiro. Disponível em: http://www.portomaravilha.com.br/conteudo/ canalInvestidor/prospecto.pdf 
MUNICÍPIO DO RIO DE JANEIRO. Segundo Prospecto. Disponível em; http:// www.bmfbovespa.com.br/pt-br/mercados/download/Porto-do-RJ-Anuncio-de-inicio.pdf

PAES, Eduardo. Para Paes, papel do PMDB é criar freios: depoimento [22 de dezembro, 2014]. Rio de Janeiro: Valor Econômico. Entrevista concedida a César Felício e Heloisa Magalhães.

PEREIRA, Paulo César Xavier. Reestruturação Imobiliária em São Paulo (SP): especificidade e tendência. In: Pereira, Paulo César Xavier; et al (Org.). Dinâmica imobiliária e reestruturação urbana na América Latina. Santa Cruz do Sul: EDUNISC, 2006.

. Megaprojeto e produção do espaço urbano: Um cavalo de Tróia? In: Oliveira, Floriano Godinho de; et al (Org.). Geografia Urbana. Ciência e Ação Política. Rio de Janeiro: Consequência, p. 199-217, 2014.

- Agentes imobiliários e reestruturação: interesses e conflitos na construção da cidade contemporânea. In: Pereira, Paulo Cesar Xavier (Org.). Negócios imobiliários e transformações sócio-territoriais em cidades da America Latina. São Paulo: FAUUSP, p. 23-31, 2011.

SEABRA, Odette Carvalho de Lima. Direito à cidade como um direito à vida urbana. Revista Advir, Rio de Janeiro, n.23, p.12-23, Julho 2014.

SMITH, Neil. Gentrificação, a fronteira e a reestruturação do espaço urbano. Revista GEOUSP - Espaço e Tempo, São Paulo, n.21, p. 15-31, 2007.

VAINER, Carlos. Cidade de Exceção: Reflexões a partir do Rio de Janeiro. In: Carlos Machado; Caio Floriano dos Santos; Claudionor Ferreira Araújo; Wagner Valente dos Passos. (Org.). Conflitos Ambientais e Urbano: Debate, Lutas e Desafios. 1ed. Porto Alegre: Evangraf, 2013.

s.a.. Grupo compra 42 imóveis históricos de ordem católica no centro do Rio. Folha de São Paulo. Disponível em: http://www1.folha.uol.com.br/fsp/cotidiano/64893-grupo-compra-42-imoveishistoricos-de-ordem-catolica-no-centro-do-rio.shtml

\section{ENDNOTES}

1. PEREIRA, Paulo Xavier, 2014, p.202.

2. Até o ano de 2015 já se contabilizaram mais de 4000 remoções de moradores mediante indenizações ou deslocamento para empreendimentos distantes da área, como os bairros de Campo Grande e Santa Cruz , no extremo oeste da cidade. Destaca-se que somente da favela doMorro da providência j[á foram removidas mais de 1.000 famílias.

\section{ABSTRACTS}

A área central do Rio de Janeiro tem sido alvo de intensas transformações urbanas a partir dos anos 2000. Para compreendemos esse processo e as questões sociais daí decorrentes, buscamos realizar uma análise sobre quais os agentes econômico-sociais envolvidos e suas práticas espaciais. Destacam-se a presença de diferentes capitais da produção imobiliária, ou seja, construtoras, incorporadores e proprietários do solo urbano. Com base na investigação acerca das incorporadoras que atuam na área central, sobretudo na área controlada por uma associação de empresas do ramo da construção civil, a Concessionária Porto Novo, avaliamos as novas características da produção social do espaço no centro da cidade do Rio de Janeiro, as implicações 
com o poder público e a submissão do projeto de reestruturação urbana da área central da cidade aos interesses de empresas imobiliárias internacionais.

The Rio de Janeiro's inner city area was the object of intense transformations since 2000. To understand this process and the social questions which rise from it, this paper addresses their economic actors and their spatial practices, stressing the presence of different capital in buildings' production, affecting builders, agencies and landowners. Through a research on the builders who work in the inner city area, and mainly in the zone controlled by the holding Concessionária Porto Novo, we evaluate the new characteristics of the social production of space in central Rio de Janeiro, their ties with public powers and the subordination to foreign capitals of the projects of urban restructuration.

Le centre de la ville de Rio de Janeiro a été l'objet d'intenses transformations urbaines à partir des années 2000. Pour comprendre ce processus et les questions sociales qui en découlent, on analyse ici les agents économiques et leurs pratiques spatiales, en soulignant la présence de différents capitaux dans la production immobilière de constructeurs, agences et propriétaires des terrains. A partir d'une recherche sur les constructeurs qui opèrent dans le centre, surtout dans l'aire contrôlée par un conglomérat d'entreprises de construction, la Concessionária Porto Novo, on évalue les nouvelles caractéristiques de la production sociale de l'espace dans le centre de Rio de Janeiro, leurs implications avec le pouvoir publique et l'assujettissement du projet de restructuration urbaine aux intérêts des entreprises immobilières internationales.

El área central de la ciudad de Río de Janeiro ha sido blanco de intensas transformaciones urbanas a partir de los años 2000. Para comprender ese proceso y las cuestiones sociales derivadas de él, analizamos los agentes económicos envueltos y sus prácticas espaciales, con énfasis en la presencia de diferentes capitales de producción inmobiliaria, tales como constructoras, incorporadores y propietarios de suelo urbano. Con base en los llamados incorporadores que actúan en el área central, sobre todo en el área controlada por una asociación de empresas del sector de la construcción civil, la Concesión Porto Novo, evaluamos las nuevas características de la producción social del espacio en el centro de la ciudad de Río de Janeiro, sus implicaciones con el poder público y la subordinación del proyecto de re-estructuración urbana a los intereses de empresas inmobiliarias internacionales.

INDEX

Mots-clés: restructuration urbaine, entreprises immobillières, Concessionária Porto Novo, aire central, ville de Rio de Janeiro.

Keywords: estate restructuration, estate projects, Porto Maravilha, inner city area, urbanization Palabras claves: re-estructuración inmobiliaria, proyectos inmobiliarios, Puerto Maravilla, área central de la ciudad de Río de Janeiro, urbanización.

Palavras-chave: reestruturação imobiliária, empreendimentos imobiliários, área central da cidade do Rio de Janeiro, urbanização

\section{AUTHOR}

\section{GABRIEL SILVA DE ARAUJO TEIXEIRA}

Universidade do Estado do Rio de Janeiro, Instituto de Geografia, gabrielgeouerj@gmail.com 